\title{
Cutaneous B cell lymphoma presenting as a soft tissue swelling
}

\author{
Arcot Rekha*, Santhosh Vivekanandan, A. Ravi \\ Sri Ramachandra University, Chennai, India; ${ }^{*}$ Corresponding Author: rekha_a@yahoo.com \\ Received 21 March 2013; revised 26 April 2013; accepted 1 May 2013 \\ Copyright (c) 2013 Arcot Rekha et al. This is an open access article distributed under the Creative Commons Attribution License, \\ which permits unrestricted use, distribution, and reproduction in any medium, provided the original work is properly cited.
}

\begin{abstract}
Cutaneous lymphomas are classified as B cell and $T$ cell lymphomas which are seen very rarely. They present as papules or nodules in the absence of any extracutaneous involvement. We present a patient who had a diffuse cutaneous $B$ cell lymphoma and review literature of this uncommon tumour.
\end{abstract}

Keywords: Cutaneous; Primary Lymphoma; Diffuse Type

\section{CASE REPORT}

A 65 years old lady presented with history of multiple nodular swellings on the body which was rapidly increasing in size over the last two months. She noticed the swelling initially in the left elbow followed by multiple swellings on the abdominal wall and hip. The swellings were occasionally pruritic. She had history of associated rashes all over the body. She had no associated photosensitivity. She had no other systemic complaints including fever, loss of weight or night sweats. Her past medical and drug history were unremarkable. She was a non-smoker and non alcoholic.

Patient was not anaemic or icteric. There was no lymphadenopathy or hepatosplenomegaly. Physical examination revealed multiple, superficial, non-tender, well defined, firm smooth swellings over the abdomen and left elbow. The largest measuring $3 \times 3 \mathrm{~cm}$ was over the abdominal wall (Figure 1).

The differential diagnosis considered was multiple lipomatosis, Von Recklinghausen's disease, desmoids tumour and cutaneous lymphoma.

Blood investigations including complete blood picture, renal function tests and liver function tests were normal. Patient was HIV negative. Fine needle aspiration cytology (FNAC) of the swelling over the elbow revealed mixed population of lymphoid cells in various stages of maturation with few polymorphs and eosinophils in a haemorrhagic background. The overall picture was suggestive of a lymph node but inconclusive. Trucut biopsy of one of the swelling from the abdomen wall was done. Sections showed closely packed sheets of neoplastic lymphoid cells with well demarcated nodular infiltrate. Immunohistochemistry studies revealed marked positivity for CD45 and CD20, with focal CD3 positive cells (immunohistochemistry as Figure 2). Sections were negative for cyclin D1, CD10 and CK. The final biopsy was suggestive of diffuse B cell type Non-Hodgkin's lymphoma.

CT scan of the whole abdomen revealed multiple nodular heterogonously enhancing mass lesions involving the subcutaneous plane of the abdominal wall, bilateral anterior parietal wall muscles and left psoas (read CT as Figure 3). The liver and spleen were normal.

Hence the diagnosis of primary cutaneous B-cell lymphoma was made. The patient was referred for further management with chemotherapy. The patient underwent 8 courses of CHOP regimen (Cyclophosphamide, Adriamycin, Vincristine and Prednisone). The patient was followed up for a year and was asymptomatic at the last review.

\section{DISCUSSION}

Cutaneous lymphomas can be classified as either B-cell or T-cell lymphoma. They are further classified as primary or secondary. Primary cutaneous B-cell lymphomas (PCBCL) are defined as malignant B-cell proliferations presenting with cutaneous involvement alone without any evidence of extra cutaneous manifestation [1]. The incidence is $0.3 / 100,000$ population per year with 65\% T-cell and 35\% B-cell types. PCBCL is 1.4 times more common in men than women. The first case was described by Kazakov et al. [2-4].

The pathophysiology of cutaneous lymphoma is only partially understood, with multiple etiological factors intervening over a long period. It is a multistep process 


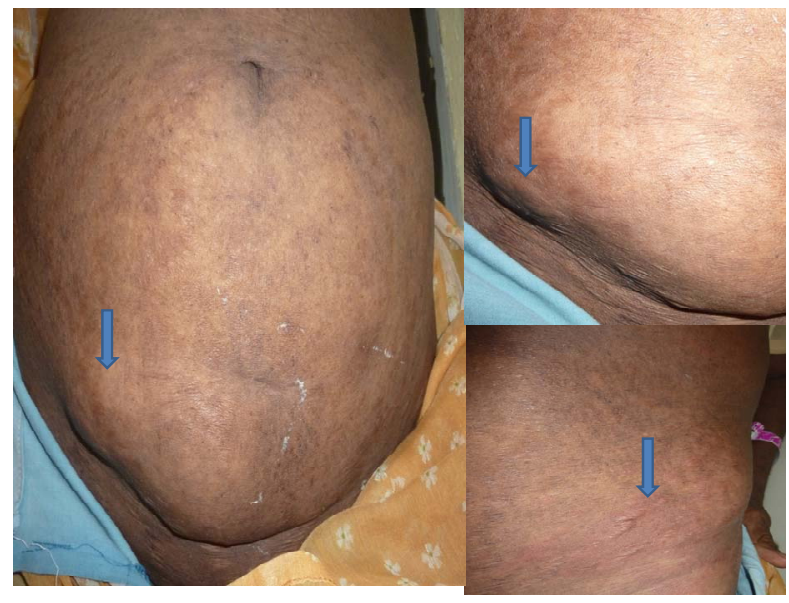

Figure 1. It shows the subcutaneous swellings with the right lower inset showing the rash and associated erythema.

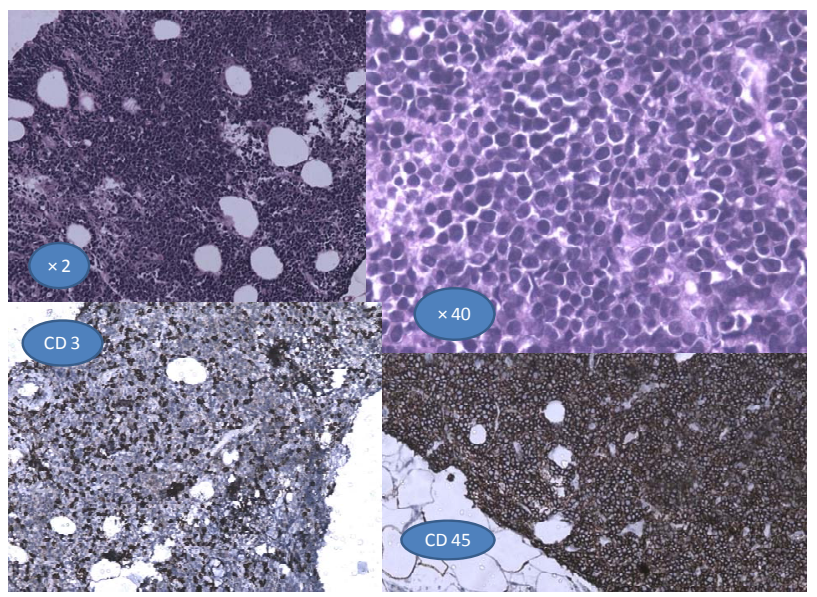

Figure 2. It shows the closely packed neoplastic cells with lymphocytic infiltrate, with the inset showing positivity for CD3 and CD45.

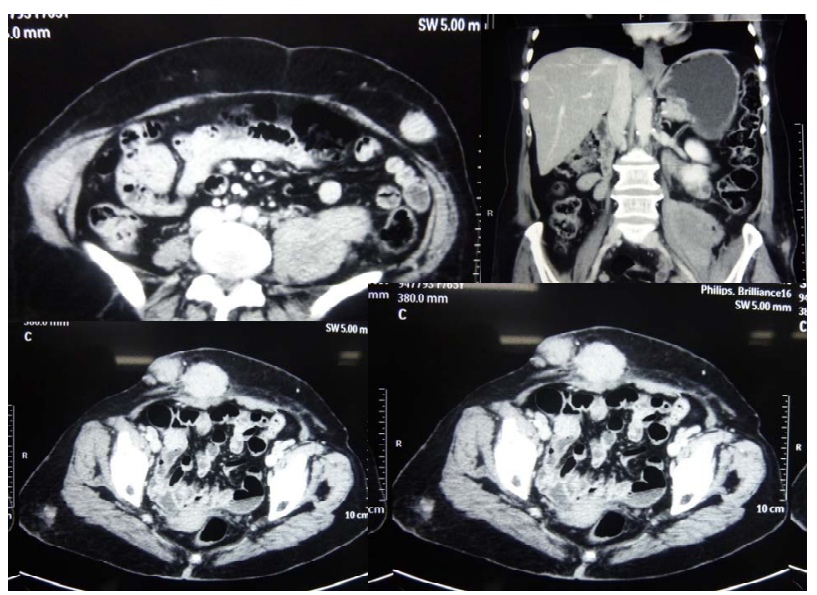

Figure 3. The CT shows the subcutaneous swellings, parietal wall swelling and the mass over the left psoas.

initially starting as a hyperreactive inflammatory process leading on to inadequate regulation of cell proliferation with insufficient oncogene and/or suppressor gene expression, promoting the preneoplastic condition into neoplasia.

The most important of these factors are immunodeficiency disorders, Infections with oncogenic viruses such as Epstein-Barr virus (EBV), Human herpes virus type 8/Kaposi sarcoma-associated herpes virus, hepatitis C virus and Infections with oncogenic bacteria such as Helicobacter pylori in mucosa associated lymphoid tissue (MALT) lymphomas, Borrelia burgdorferi (CBCL) [5-7].

Borrelia burgdoferi is associated with a significant number of cases in western population but it has not been reported in Asian cases. The current theory suggests that Borrelia infection chronically stimulate lymphoid tissue acquired in the skin.

The World Health Organization and European Organization of Research and Treatment of Cancer (WHOEORTC) classify cutaneous lymphomas into three types, the cutaneous T-cell and natural killer (NK) lymphomas, the cutaneous B-cell lymphomas (CBCL), and the precursor hematologic neoplasms. The B-cell lymphoma (CBCL) includes Primary cutaneous follicle center lymphoma, Primary cutaneous marginal zone B-cell lymphoma (mucosa-associated lymphoid tissue [MALT] type), Cutaneous diffuse large B-cell lymphoma and Intravascular large B-cell lymphoma [3].

Typically the lesions are found over trunk, upper limbs, axilla and back. The lesion can present as papule, plaque or nodule. Multiple lesions are found most often. Ulceration is uncommon. Unlike in T-cell variety, pruritis is uncommon. Extracutaneous involvement occurs as a late feature.

The diagnosis is based on history, clinical examination, analysis of skin biopsy specimen using immunohistochemistry, phenotypic features, genotyping studies, histomorphology and cytomorphology.

CBCL exhibits a typical B-cell growth pattern characterized by a well demarcated nodular infiltrate of lymphoid cells in the dermis. The subepidermal grenz zone and the interstitial zone are usually free of infiltration. Epidermotropism is absent in CBCL. The infiltrating cells are usually small lymphocytes or the cellular components of the lymph follicle such as centrocytes, centroblasts, immunoblasts, mantle cells or plasma cells. Dutcher bodies, which are intranuclear PAS positive pseudoinclusions are seen in the plasma cells. Reactive germinal centres are also frequently involved. The epidermis is involved only in rare cases.

Immunohistochemistry plays a crucial role in the diagnosis, showing strong positivity for CD5 (B-cell chronic lymphatic leukaemia), CD20, CD79a, CD21 (Follicular dendritic cells), CD10, Mum-1/IRF4, bcl-2, bcl-6, kappa and lambda chains. Translocation of the BCL2 
gene is usually negative in CBCL, although seen in nodal follicular lymphoma [8,9].

The genetic defects in cutaneous lymphoma are heterogenous, hence genotyping is of limited diagnostic value. Other investigations like Chest X-ray, ultrasonography and CT scanning of the abdomen and peripheral lymph nodes are useful only in advanced skin disease with palpable lymphadenopathy and to document disease progression.

CBCLs have very good prognosis hence overtreatment must be avoided. Aggressive systemic treatment is advised for diffuse large B-cell lymphoma and for patients with extracutaneous involvement.

Treatment options include radiotherapy, excision, systemic chemotherapy or a combination of these modalities. The management depends on whether the lesion is solitary or multifocal, and whether the disease is at its initial presentation or recurrence [10-12].

If solitary, then surgery is the treatment of choice. Radiotherapy alone has got a high rate of local relapse, therefore systemic therapies is preferred to local therapy.

The treatment for diffuse large B-cell lymphoma with multiple lesions which is associated with poor prognosis include monochemotherapy with liposomal doxorubicin at $20-40 \mathrm{mg} / \mathrm{m}^{2}$ IV every 2 - 4 weeks or polychemotherapy (Chlorambucil, cyclophosphamide, doxorubicin, vincristine and prednisolone) with anti CD20 antibody (Rituximab) and interferon 2a [13,14]. A trial of systemic antibodies for borrelia infection in endemic areas can also be tried. Antibiotic treatment consists of doxycycline at $100 \mathrm{mg}$ twice daily for 3 weeks or pulse therapy with cefotaxime in Borrelia-associated cases [7].

Radiotherapy options include 20 - $100 \mathrm{kV}$ orthovolt therapy one to four times per week, to a total dose upto 15 - 20 Gy, Extended field irradiation at 30 Gy or localized field irradiation [15].

Second line treatments include intralesional injection of glucocorticosteroids, rituximab or interferon alpha.

Patient should be followed up at least every 6 months for a clinical workup. Additional laboratory and imaging workup is not required unless enlargement of the regional lymph nodes is present.

\section{CONCLUSION}

The surgeon rarely encounters lymphomas presenting as subcutaneous soft tissue swellings. Knowledge of this uncommon B cell lymphoma is necessary for recognition, diagnosis and early referral to the oncologist as this tumour has a relatively good prognosis.

\section{REFERENCES}

[1] Odom, R.B., James, W.D. and Berger, T.G. (2000) Cutaneous lymphoid hyperplasia, cutaneous T-cell lymphoma, other malignant lymphomas, and allied diseases. In: Andrews' Diseases of the Skin, Clinical Dermatology. 9th Edition, W.B. Saunders Company, Philadelphia, 918-942.

[2] Fink-Puches, R., Zenahlik, P., Bäck, B., Smolle, J., Kerl, H. and Cerroni, L. (2002) Primary cutaneous lymphomas: Applicability of current classification schemes (EORTC, WHO) based on clinicopathologic features observed in a large group of patients. Blood, 99, 800-805. doi:10.1182/blood.V99.3.800

[3] Willemze, R., Kerl, H., Sterry, W., et al. (1997) EORTC classification for primary cutaneoulymphomas: A proposal from the Cutaneous Lymphoma Study Group of the European Organization for Research and Treatment of Cancer (EORTC). Blood, 90, 354-371.

[4] Goodlad, J.R., Krajewski, A.S., Batstone, P.J., et al. (2003) Primary cutaneous diffuse large B-cell lymphoma: Prognostic significance and clinicopathologic subtypes. American Journal of Surgical Pathology, 27, 1538-1545. doi:10.1097/00000478-200312000-00006

[5] Nagore, E., Ledesma, E., Collado, C., Oliver, V., PérezPérez, A. and Aliaga A. (2000) Detection of Epstein-Barr virus and human herpesvirus 7 and 8 genomes in primary cutaneous T- and B-cell lymphomas. British Journal of Dermatology, 143, 320-323. doi:10.1046/j.1365-2133.2000.03657.x

[6] Ichiyama, S., Yokote, T., Iwaki, K., Miyoshi, T., Takubo, T., Tsuji, M. and Hanafusa, T. (2011) Co-infection of human herpesvirus- 6 and human herpesvirus- 8 in primary cutaneous diffuse large B-cell lymphoma, leg type. British Journal of Haematology, 155, 514-516. doi:10.1111/j.1365-2141.2011.08702.x

[7] Garbe, C., Stein, H., Dienemann, D. and Orfanos, C.E. (1991) Borrelia burgdorferi-associated cutaneous B cell lymphoma: Clinical and immunohistologic characterization offour cases. Journal of the American Academy of Dermatology, 24, 584-590. doi:10.1016/0190-9622(91)70088-J

[8] Cerroni, L., Volkenandt, M., Rieger, E., Soyer, H.P. and Kerl, H. (1994) bcl-2 protein expression and correlation with the interchromosomal 14;18 translocation in cutaneous lymphomas and pseudolymphomas. Journal of Investigative Dermatology, 102, 231-235. doi:10.1111/1523-1747.ep12371768

[9] Grange, F., Bekkenk, M.W., Wechsler, J., et al. (2001) Prognostic factors in primary cutaneous large B-cell lymphomas: A European multicenter study. Journal of Clinical Oncology, 19, 3602-3610.

[10] Zinzani, P.L., Quaglino, P., Pimpinelli, N., et al. (2006) Prognostic factors in primary cutaneous B-cell lymphoma: The Italian study group for cutaneous lymphomas. Journal of Clinical Oncology, 24, 1376-1382. doi:10.1200/JCO.2005.03.6285

[11] Zenahlik, P., Fink-Puches, R., Kapp, K.S., Kerl, H. and Cerroni, L. (2000) Therapy of primary cutaneous B-cell lymphomas. Hautarzt, 51, 19-24. doi:10.1007/s001050050005

[12] Dreno, B. (2006) Standard and new treatments in cutaneous B cell lymphoma. Journal of Cutaneous Pathology, 33, 47-51. 
[13] Heinzerling, L.M., Urbanek, M., Funk, J.O., et al. (2000) Reduction of tumor burden and stabilization of disease by systemic therapy with anti-CD20 antibody (rituximab) in patients with primary cutaneous B-cell lymphoma. Cancer, 89, 1835-1844. doi:10.1002/1097-0142(20001015)89:8<1835::AID-CNC R26>3.0.CO;2-H

[14] Peñate, Y., Hernández-Machín, B., Pérez-Méndez, L.I., Santiago, F., Rosales, B., Servitje, O., Estrach, T., Fernández-Guarino, M., Calzado, L., Acebo, E., Gallardo, F., Salar, A., Izu, R., Ortiz-Romero, P.L., Pujol, R.M. and
Fernández-de-Misa, R. (2012) Intralesional rituximab in the treatment of indolent primary cutaneous B-cell lymphomas: An epidemiological observational multicentre study. The Spanish Working Group on Cutaneous Lymphoma. British Journal of Dermatology, 167, 174-179. doi:10.1111/j.1365-2133.2012.10902.x

[15] Pashtan, I., Mauch, P.M., Chen, Y.H., Dorfman, D.M., Silver, B. and Ng, A.K. (2012) Radiotherapy in the management of localized primary cutaneous B-cell lymphoma. Leukemia \& Lymphoma, 54, 726-730. 